\title{
Treatment of asthma in preschool children with slow release theophylline
}

\author{
B G LOFTUS AND J F PRICE
}

Department of Child Health and Chest Unit, King's College Hospital, London

SUMMARY Fifty two preschool children with asthma were given a recommended regimen of slow release theophylline. There was wide variation in the metabolism of theophylline. The approach adopted gave disappointing results. Nine children did not comply, and 16 stopped treatment because of side effects. Of the remainder, control of asthma was poor in 15 and satisfactory in 12 .

Slow release theophylline is often used in the management of preschool children with asthma. A placebo controlled trial showed beneficial effects in this age group when doses were adjusted to give concentrations of $10-20 \mathrm{mg} / \mathrm{l}^{1}$

We report our experience with slow release theophylline using a recommended treatment regimen ${ }^{2}$ in young children with moderately severe asthma.

\section{Patients and methods}

Fifty two children, 36 boys and 16 girls aged 18-69 months (mean 42), began treatment with slow release theophylline between September 1983 and May 1984. The indications for this treatment were one or more severe attacks of asthma each month or symptoms of asthma on most days. Thirty three children had been admitted to hospital at least once in the year before the study. Sucrose based pellets of slow release theophylline in capsules (Slo-Phyllin, Lipha Pharmaceuticals) were administered twice daily in an initial dose as close to $16 \mathrm{mg} / \mathrm{kg} /$ day as possible. In most cases the capsules were opened and the granules taken with food.

After one month of treatment concentrations of theophylline in the blood were measured two to six hours after a morning dose, and the dose was adjusted if necessary to give blood concentrations in the range of 10-20 mg/l. The children were assessed at one to two monthly intervals by one of us (BGL) for a period of four to 10 months. Control of asthma was deemed inadequate if admission to hospital or repeated courses of steroids was required or if symptoms persisted on most days. Side effects were not specifically elicited and were recorded only when volunteered by the childrens' parents.

\section{Results}

Initial dosage of theophylline ranged from 14 to $23 \mathrm{mg} / \mathrm{kg} /$ day (mean 18). The wide range of dosage was due to limitations imposed by the size of capsules. Six patients stopped treatment before blood concentrations were measured, three had concentrations of $0 \mathrm{mg} / \mathrm{l}$, and blood concentrations of the remaining 43 ranged from 3-21 mg/l (mean 9) (Figure). Dosage was increased in 27 . Subsequently, two patients were non-compliant, and in the others concentrations ranged from $5-25 \mathrm{mg} / \mathrm{l}$ (mean 13). One child needed a further increase in dosage. The final dose required to achieve therapeutic blood concentrations ranged from 16 to $31 \mathrm{mg} / \mathrm{kg} /$ day (mean 21).

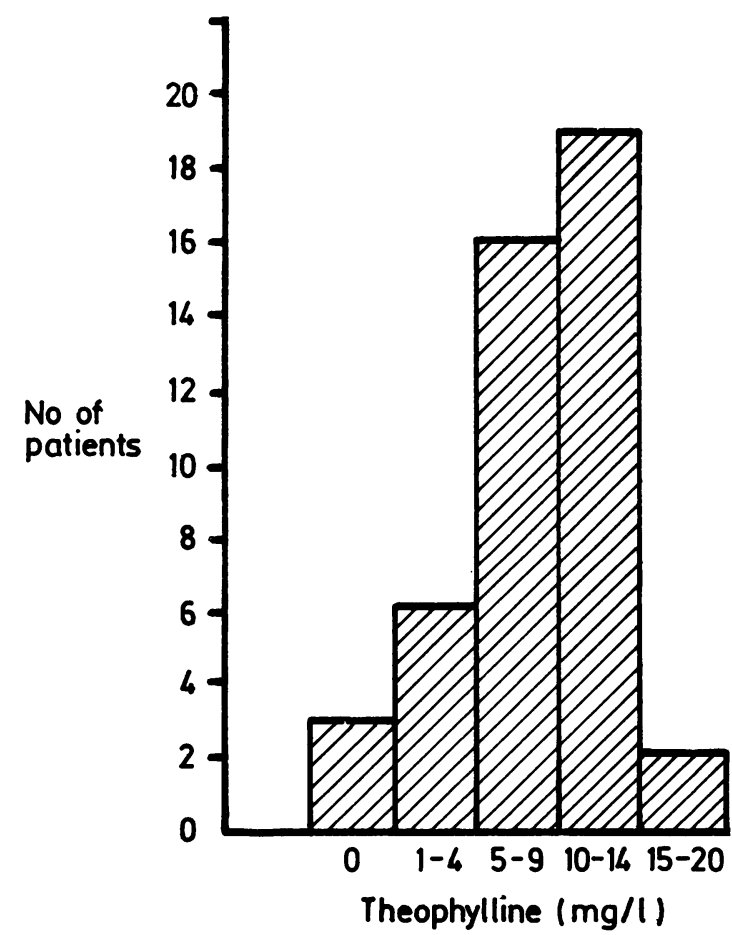

Figure Theophylline concentrations after initial dosage. Range 14-23 $\mathrm{mg} / \mathrm{kg} /$ day 
Table Clinical characteristics and outcome of treatment in 43 children with moderately severe asthma*

\begin{tabular}{lcc}
\hline & Treatment stopped & Inadequate control \\
\hline No & 16 & 15 \\
Mean (range) age (months) & $41(20-64)$ & $42(22-68)$ \\
Sex & $10 \mathrm{M}, 6 \mathrm{~F}$ & $7 \mathrm{M}, 6 \mathrm{~F}$ \\
No admitted to hospital in previous year & 7 & 12 \\
No with chest deformity & 10 & $122-69)$ \\
Mean (range) final dose (mg/kg/day) & $20(14-31)$ & 9 \\
Mean (range) final blood theophylline mg/l & $12(10-13)$ & 9 \\
\hline
\end{tabular}

* The nine non-compliant patients are not included.

Nine patients were non-compliant. Four initially took the preparation but subsequently refused it, and five others were supposedly taking treatment but had blood concentrations of $0 \mathrm{mg} / \mathrm{l}$ (in two after the dose had been increased). Sixteen patients stopped treatment because of side effects, 10 while taking the initial dosage and six when the dose was increased because of low blood concentrations. Symptoms associated with withdrawal of treatment were vomiting (in nine patients), behavioural disturbance (six), and nightmares (one). In all but two patients these symptoms resolved when treatment with theophylline was stopped.

Control of asthma was satisfactory in 12 of the remaining 27 children, when therapeutic blood concentrations of theophylline were achieved. Asthma in 15 children was inadequately controlled; eight required admission to hospital, three needed repeated courses of steroids, and four had regular persistent symptoms. Therapeutic concentrations of theophylline were shown in 11 of these children. In the four others therapeutic concentrations were not noted when treatment was stopped, but the initial blood concentrations were between $5-9 \mathrm{mg} / \mathrm{l}$ and doses had been appropriately increased. Clinical characteristics, final dosage, and blood concentrations were similar in all compliant patients (Table).

\section{Discussion}

Slow release theophylline has some beneficial effect in young asthmatic children. ${ }^{1}$ Theophyllines can, however, cause unwanted side effects, and the proportion of patients unable to tolerate treatment may be high. ${ }^{3}$ The children we enrolled followed a strict treatment regimen, determined at the start of the study and based on recommendations. Our purpose was to assess this treatment regimen.

We observed a wide range of blood concentrations with the initial dose. This dose, related to body weight, was not consistent as there were only a limited number of capsule sizes available. There was no clear relation, however, between the initial doses and the corresponding blood concentrations, con- firming that children show considerable individual variation in the way they absorb and metabolise theophylline ${ }^{4}$ About half of the children we studied needed an adjustment in dose and further blood tests before therapeutic concentrations were achieved.

Clearly, the therapeutic approach that we adopted gave unsatisfactory results. Side effects were common. To some extent their occurrence was dependent on the dose given, but one fifth of the patients volunteered adverse symptoms when given the initial dose. Six patients who stopped treatment because of side effects, were known to have had blood concentrations that were within the therapeutic range. The two patients with concentrations greater than $20 \mathrm{mg} / \mathrm{l}$ had no symptoms of toxicity.

Of those children who tolerated treatment that gave therapeutic theophylline blood concentrations, less than half had satisfactory control of asthma. Some children had more severe asthma than others, but outcome was not predictable on the basis of clinical characteristics at entry (Table). One of our main criteria for good control of asthma was the prevention of severe attacks of asthma, and theophyllines may not be effective in preventing such attacks. ${ }^{5}$

Side effects of treatment with theophylline may be reduced by using an even lower initial dosage and gradually increasing it. Acceptance of the drug may be improved if parents are warned of side effects and the transient nature of some of these are emphasised. The use of relatively large doses twice daily may result in high therapeutic concentrations after the dose is given and subtherapeutic concentrations before the dose is given. This could account for the high incidence of side effects and the poor efficacy seen. Treatment with smaller doses eight hourly would be more inconvenient to administer but might improve outcome by maintaining blood concentrations in the therapeutic range for 24 hours. ${ }^{6}$

\footnotetext{
References

' Stratton D, Carswell F, Hughes AD, Fysh WJ, Robinson P. Double-blind comparisons of slow-release theophylline, keto-
} 
tifen and placebo and prophylaxis of asthma in young children. Br J Dis Chest 1984;78:163-7.

2 Phelan PD, Landau LI, Olinsky A, (eds). Respiratory illness in children. Oxford: Blackwell Scientific Publications, 1982:186.

${ }^{3}$ Hambledon G, Weinberger M, Taylor J, et al. Comparison of cromoglycate and theophylline in controlling symptoms of chronic asthma. Lancet 1977; $\mathbf{i} 381$.

${ }^{4}$ Ellis PE, Koysooko R, Levy G. Pharmacokinetics of theophylline in children with asthma. Pediatrics 1976;54:542-7.

${ }^{5}$ Wilson $N$, Silverman $M$. Controlled trial of slow-release aminophylline in childhood asthma: are short term trials valid? Br Med J 1982;284:863.

- Simons FSR, Lucuik GH, Simons KJ. Sustained release theophylline for treatment of asthma in pre-school children. Am J Dis Child 1982;136:790.

Correspondence to Dr B G Loftus, Chest Unit, King's College Hospital, London SE5 8RX.

Received 12 March 1985

\title{
Lactation nurse increases duration of breast feeding
}

\author{
D A JONES AND $R$ R WEST
}

Department of Community Medicine, Welsh National School of Medicine, Cardiff

SUMMARY In a randomised controlled trial a lactation nurse assisted mothers during the early weeks after parturition both in hospital and at home. All mothers who started breast feeding were entered into the trial. The lactation nurse significantly extended duration in the study group compared with controls, particularly during the first four weeks and among women of lower social class.

Breast milk is considered to be the milk most suitable for the health and wellbeing of most babies. ${ }^{1}$ Researchers and experts, however, have drawn attention to the paucity of advice on breast feeding within and without hospital, and the lack of consistency of such advice..$^{2-4}$ Inadequate assistance for mothers wishing to breast feed has contributed to the unacceptably high rate of premature cessation of breast feeding and consequently to disappointment of mothers. There was therefore a need to evaluate the benefits of employing a specially trained midwife whose role was to assist and encourage mothers in the early days of breast feeding both in hospital and in their own homes. The most rigorous evaluation is by means of a randomised controlled trial.

\section{Methods}

A total of 1525 mothers $(98.7 \%)$ delivering in the maternity department of a district general hospital over a period of 18 months were interviewed as soon as possible after delivery. All mothers who attempted to breast feed at least once (the study group, $n=678$ ) were entered into a randomised controlled trial to evaluate the effectiveness of a lactation nurse on establishing and maintaining breast feeding. She worked in the maternity wards in two week shifts followed by two week shifts visiting the same mothers at home, so that mothers were randomised in terms of two week periods. Intervention group mothers were those who gave birth and left hospital during the 'intervention period' when the nurse was in hospital. Controls were those who gave birth and left hospital during a 'control period' when the nurse was visiting cases at home. It was decided previously that those whose confinement overlapped both intervention and control periods should be excluded in order to avoid 'contamination' between cases and controls.

The nurse's role was to assist mothers to establish and maintain successful breast feeding in hospital and at home. This required assisting mothers to 'fix' babies on the breast, thereby preventing complications that often lead to cessation of breast feeding such as sore nipples and engorgement, and advising on treatment of these problems if they occurred. As well as these specific activities she provided support, encouragement, and consistent advice.

Table 1 Duration of breast feeding in intervention and control groups (number (\%) still feeding at each point in time)

\begin{tabular}{lll}
\hline Time & $\begin{array}{l}\text { Intervention } \\
(n=228) \\
\text { No }(\%)\end{array}$ & $\begin{array}{l}\text { Controup } \\
(n=355) \\
\text { No }(\%)\end{array}$ \\
\hline $1 \mathrm{wk}$ & $215(94)$ & $307(86)$ \\
$2 \mathrm{wks}$ & $208(91)$ & $289(81)$ \\
$4 \mathrm{wks}$ & $191(84)$ & $255(72)$ \\
$3 \mathrm{mths}$ & $138(61)$ & $175(49)$ \\
$6 \mathrm{mths}$ & $86(38)$ & $98(28)$ \\
$9 \mathrm{mths}$ & $34(15)$ & $51(14)$ \\
$12 \mathrm{mths}$ & $9(4)$ & $25(7)$ \\
\hline
\end{tabular}

